\title{
Spina bifida and parental occupation in a Swedish register-based study
}

\author{
by Birgitte M Blatter, MSc, ${ }^{1}$ Nel Roeleveld, $P h D^{1}$
}

\begin{abstract}
Blatter BM, Roeleveld N. Spina bifida and parental occupation in a Swedish register-based study. Scand J Work Environ Health 1996:22:433-7.
\end{abstract}

Ohjectives To gather more evidence on a possible relation between spina bifida and agricultural and other occupations of parents, a register-based linkage study was conducted in Sweden.

Methods Four hundred and eighty-two cases of spina bifida in infants born between 1976 and 1991 were identified from the Swedish Register of Congenital Malformations. Nine hundred and sixty-four referents without spina bifida were selected from the Medical Birth Register and matched for year of birth of the child, maternal age, and parity. Information on occupation was obtained from the Medical Birth Register from 1983 on, and from the census, which is performed every fifth year.

Results A slightly increased odds ratio (OR) was observed for women in agricultural occupations [OR 1.8, $95 \%$ confidence interval $(95 \%$ CI $) 0.8-4.2]$. For all women who had an agricultural occupation or lived on a farm, the $\mathrm{OR}$ was $2.2(95 \% \mathrm{CI} 1.3-3.8)$. The $\mathrm{OR}$ values of most of the other occupational groups were close to unity.

Conclusions The results suggest an increased risk of spina bifida for the infants of women in agricultural occupations, but they do not provide insight into any specific occupational risk factors.

Key terms birth defects, neural tube defects, occupational exposure.

As spina bifida exhibits a strong variation by socioeconomic status in several countries (1), a search for environmental causes is indicated. Since classifications of socioeconomic status are primarily based on occupation, the presence of potential teratogens in the work environment may be an explanation for the differential prevalence rates by socioeconomic class, in addition to differing life-style factors. Maternal occupational exposure around conception and up to the 28th day of embryonic development could have a direct effect on the morphogenesis of the neural tube. Paternal chemical occupational exposure could theoretically result in genetic damage to germ cells (2) and introduce teratogenic substances in the seminal fluid at conception or later during embryonic development $(3,4)$.

Studies specific to neural tube defects and parental occupation have been scarce. Most studies include congenital anomalies in general or defects of the central nervous system (CNS) as a group, including neural tube defects. In these studies, some associations have been found for women working in industry, construction, transport and communication $(5,6)$, dental surgeries (7), and nursing (8) and for women exposed to organic sol- vents (9). Studies on fathers yielded increased risks for painters (10), agricultural workers (11), workers in the food, beverage, wood and textile industries (12), and fathers exposed to low-level radiation (13).

Studies that focused on neural tube defects in particular or on one of the main categories of congenital defects have revealed increased risks for women working as hairdressers (14) and farmers $(14,15)$ and for men working as painters (16-18), printers, decorators, transport and communication workers (16), plastic production workers (18), and farmers and bricklayers (14). It should be stressed, however, that, except for male painters and male and female agricultural workers, very few findings have been repeated in two or more studies.

Recently, we conducted a case-referent study on spina bifida and parental occupation in The Netherlands. Postal questionnaires and personal interviews were used to collect data on occupation and occupational exposure, respectively. Increased risks were suggested for fathers working as a welder or transport worker, for cleaningwomen, and, especially, for women working in agriculture [odds ratio (OR) 5.6, 95\% confidence interval (95\% CI) $1.8-17.8]$ (19). However, no association was

1 Department of Medical Informatics, Epidemiology and Statistics, University of Nijmegen, The Netherlands.

Reprint requests to: Ms Birgitte M Blatter, Department of Medical Informatics, Epidemiology and Statistics, University of Nijmegen, PO Box 9101, 6500 HB Nijmegen, The Netherlands. 
found between spina bifida and maternal pesticide use or any other agriculture-related exposure, but the numbers of exposed workers were small (20). A Finnish study did not find an association between pesticide use and CNS defects either (21).

To gather more evidence about a potential relation between spina bifida and parental agricultural occupations, we conducted a register-based case-referent study. Furthermore, we also evaluated the risk of other occupations with a potential for chemical or physical exposure.

\section{Subjects and methods}

\section{Subjects}

The subjects were identified from the Swedish Register of Congenital Malformations (22). This register became compulsory in 1965 and covers live births, stillbirths, and prenatally diagnosed malformations from all of Sweden from 1973 on. Using the unique personal identification number of the mother or the child or both, the register was linked with the Medical Birth Register, which covers all live births and stillbirths in Sweden from 1973 on. The maternal identification numbers and birthdates of the children could be used to determine whether the same case appeared in both registers.

In this study, 482 infants with spina bifida aperta [International Classification of Diseases (ICD-9) codes 741.0 and 741.9] (23) were included. Because occupational information was not available for every year of birth of the children, we could only include children born in 1976, 1981, or between 1983 and 1991. As a consequence of the linking procedure, only live births and stillbirths have been included in our study. For each case, two referents without spina bifida were selected from the Medical Birth Register, matched for year of birth of the child, maternal age in five-year classes, and parity (first, second, third, and fourth or subsequent child). As a result, 964 referents were included.

\section{Data collection}

Information on occupation was obtained from two sources. The first source of occupational information was the census, which was linked with the Medical Birth Register. Performed every fifth year, the census provides a large amount of information on each individual in Sweden. Census information on maternal and paternal occupation is coded centrally by Statistics Sweden using the Nordic Classification of Occupations. In this casereferent study the three-digit code was used. Because of a special interest in agriculture and the fact that farming occupations may be underreported by women, we also abstracted information on housing, particularly living on a farm, from the census. Census information from 1975 was used for infants born in 1976, from 1980 for infants born in 1981, and from 1985 for infants born in 1985 or 1986. Information on paternal occupations was only available in the census from 1985, which was linked with births in 1985 and 1986.

The second source of occupational information was the Medical Birth Register, which has been collecting information on maternal occupation since 1983. The occupational information in the Medical Birth Register is based on interviews performed by midwives at the first visit of the pregnant woman to the maternity health service, usually at weeks $10-12$. The actual occupation of the woman is recorded verbatim. In the present study this information was translated into the three-digit code of the Nordic Classification of Occupations for infants, who were born between 1983 and 1991. The coding was done without knowledge of the case-referent status of the child.

To assess whether someone had an occupation with potential exposure to chemical or physical agents, we primarily used the census information on occupation. As more-detailed information on occupation is gathered in the census, it is more often precise and complete. When no census information was available, the occupational information in the Medical Birth Register was used. Table 1 shows the distribution of the cases and referents according to year of birth and the source of information that was used to assess the occupation of the mothers in that specific year of birth. Census information was used for one-third of all the cases and referents; the Medical Birth Register was used in all other cases. The table also shows the years in which information on housing, smoking, socioeconomic status, and geographic area was available.

\section{Analysis}

Matched univariate analyses were done for the triplets of the cases and referents, odds ratios (OR) being calculated by means of Mantel-Haenszel estimates with $95 \%$ confidence intervals (24). We included smoking in three classes (no smoking, $0-10$ cigarettes, $>10$ cigarettes), socioeconomic status in four classes (blue-collar workers, middle-class white-collar workers, academics and executives, and farmers) and geographic area in five classes (southeast, south, southwest, middle, and north) as potential confounders. The subjects whose status was unknown due to lack of data were not excluded from the analyses but were instead included as a separate category.

\section{Results}

Table 2 presents the distributions of the maternal agricultural occupations and other selected maternal occupa- 
Table 1. Cases and referents by year of birth and source of information on occupation, socioeconomic status, housing, smoking, and geographic area. (MBR = Medical Birth Register)

\begin{tabular}{|c|c|c|c|c|c|c|c|}
\hline \multirow[t]{2}{*}{ Year of birth } & \multirow{2}{*}{$\begin{array}{l}\text { Cases } \\
(\mathrm{N})\end{array}$} & \multirow{2}{*}{$\begin{array}{l}\text { Referents } \\
\text { (N) }\end{array}$} & \multicolumn{5}{|c|}{ Source of information } \\
\hline & & & $\begin{array}{c}\text { Maternal } \\
\text { occupation }\end{array}$ & $\begin{array}{l}\text { Socioeconomic } \\
\text { status }\end{array}$ & Housing & Smoking & $\begin{array}{c}\text { Geographic } \\
\text { area }\end{array}$ \\
\hline 1976 & 46 & 92 & Census & . & census & . & MBR \\
\hline 1981 & 41 & 82 & Census & . & census & & MBR \\
\hline 1983 & 38 & $7 \overline{6}$ & MBR & . & . & MBR & MBR \\
\hline 1984 & 41 & 82 & MBR & . & . & MBR & MBR \\
\hline 1985 & 48 & 96 & Census & census & census & MBR & MBR \\
\hline 1986 & 53 & 106 & Census & census & census & MBR & MBR \\
\hline 1987 & 66 & 132 & MBR & $\cdot$ & $\cdot$ & MBR & MBR \\
\hline 1988 & 41 & 82 & MBR & . & . & MBR & MBR \\
\hline 1989 & 54 & 108 & MBR & . & . & MBR & MBR \\
\hline 1990 & 52 & 104 & MBR & . & . & MBR & MBR \\
\hline 1991 & 2 & 4 & MBR & . & . & MBR & MBR \\
\hline Total & 482 & 964 & . & & . & - & \\
\hline
\end{tabular}

tions with potential for chemical exposure. Of the case mothers, 130 were housewives and $339(70 \%)$ worked outside the home, compared with 230 and 708 (73\%), respectively, of the reference mothers. The remaining mothers were students or had occupations that could not be classified.

An increased risk was observed for women in agricultural occupations (OR 1.8, 95\% CI 0.8 -4.2). Five case mothers and seven reference mothers were working proprietors in agriculture, two case mothers were livestock or poultry farm workers, two case mothers and three reference mothers were horticultural workers, and one case mother and one reference mother were furbearing animal workers. When we included all women who had an agricultural occupation or lived on a farm in the exposed category, the odds ratio increased to 2.2 (95\% CI 1.3-3.8).

Although our main interest focused on agricultural occupations, we were also able to study associations between spina bifida and some other potentially exposed occupations. A decreased odds ratio of $0.2(95 \% \mathrm{CI}$ $0.0-1.4$ ) was observed for hairdressers. No effect was found for the total group of industry and transport workers (OR 1.0), but when only women who worked in the printing, paper or plastic industry were considered, an increased odds ratio of 1.7 (95\% CI $0.6-5.0)$ was seen. However, the numbers were small and the confidence interval did not exclude unity. The odds ratios of all the other occupational categories were close to unity.

Only 81 case fathers and 162 reference fathers could be included in the analysis due to lack of data on paternal occupation (table 3 ). Increased odds ratios were found for paternal agricultural occupations (OR 1.6, 95\% CI $0.6-4.5$ ), and for solvent-exposed fathers (OR 2.6, 95\% CI $0.7-10.4)$. However, the $95 \%$ confidence intervals for both odds ratios did not exclude unity.

Smoking, socioeconomic status, and geographic area were included in the analyses as potential confounders.
Table 2. Number of cases and referents and Mantel-Haenszel odds ratios (OR) with $95 \%$ confidence intervals $(95 \% \mathrm{Cl}$ ) for maternal occupational categories with potential exposure to chemical or physical agents compared with a group comprised of unexposed occupations and housewives.

\begin{tabular}{|c|c|c|c|c|}
\hline Occupation & $\begin{array}{c}\text { Cases } \\
(N=482)\end{array}$ & $\begin{array}{l}\text { Referents } \\
(\mathrm{N}=964)\end{array}$ & $\mathrm{OR}$ & $95 \% \mathrm{Cl}$ \\
\hline Agricultural workers & 10 & 11 & 1.8 & $0.8-4.2$ \\
\hline All agricultural women ${ }^{\mathrm{a}}$ & 32 & 30 & 2.2 & $1.3-3.6$ \\
\hline Nurses & 16 & 29 & 1.1 & $0.6-2.1$ \\
\hline Nurse's aides & 52 & 119 & 0.9 & $0.6-1.2$ \\
\hline Other health care workers & 18 & 49 & 0.7 & $0.4-1.3$ \\
\hline Cleaners & 16 & 28 & 1.2 & $0.6-2.1$ \\
\hline Hairdressers & 1 & 9 & 0.2 & $0.0-1.4$ \\
\hline $\begin{array}{l}\text { Industry and transport } \\
\text { workers }\end{array}$ & 22 & 43 & 1.0 & $0.6-1.7$ \\
\hline $\begin{array}{l}\text { Printing, paper and } \\
\text { plastic workers }\end{array}$ & 6 & 7 & 1.7 & $0.6-5.0$ \\
\hline $\begin{array}{l}\text { Unexposed occupations } \\
\text { and housewives }\end{array}$ & 334 & 650 & & \\
\hline
\end{tabular}

a Exposed: maternal agricultural occupation or living on a farm.

They did not confound the relation between spina bifida and maternal or paternal occupation

\section{Discussion}

The results of this register-based study point to a slightly increased risk for women working in agriculture. When only women with agricultural occupations were assigned to the exposed category, an odds ratio of 1.8 was observed (95\% CI 0.8-4.2). However, women who perform agricultural tasks at home may call themselves housewives and may thus be misclassified with respect to exposure status. Therefore, women living on a farm were included in the exposed category as well, yielding an odds ratio of 2.2 (95\% CI 1.3-3.8). As information on housing was only available for births in 1976, 1981, 
Table 3. Number of cases and referents and the Mantel-Haenszel odds ratios $(O \mathrm{R})$ with $95 \%$ confidence intervals $(95 \%, \mathrm{Cl})$ for paternal occupational categories with potential exposure to chemical or physical agents and a group comprised of unexposed occupations.

\begin{tabular}{lcccc}
\hline Occupation & $\begin{array}{c}\text { Cases } \\
(\mathrm{N}=81)\end{array}$ & $\begin{array}{c}\text { Referents } \\
(\mathrm{N}=162)\end{array}$ & OR & $95 \% \mathrm{Cl}$ \\
\hline Agricultural workers & 7 & 9 & 1.6 & $0.6-4.5$ \\
Health care & 0 & 3 &. &. \\
$\begin{array}{l}\text { Transport and communication } \\
\text { Workers }\end{array}$ & 5 & 14 & 0.7 & $0.2-2.0$ \\
$\begin{array}{l}\text { Industrial workers } \\
\text { Printing, painting, paper }\end{array}$ & 24 & 45 & 1.1 & $0.6-1.9$ \\
and plastic workers & 5 & 4 & 2.6 & $0.7-10.4$ \\
Unexposed occupations & 45 & 91 &. &. \\
\hline
\end{tabular}

1985, and 1986, however, some people may still be mis classified according to this broader definition.

The rather broad category of agricultural workers that we used in this study may comprise a diversity of tasks and activities and varying chemical or physical exposures. Due to small numbers, however, it was not possible to subdivide this category into homogeneously exposed groups. As a result, random misclassification might have biased the odds ratios towards the null value.

In our study, infants with spina bifida were selected from the Register of Congenital Malformations. In this register, every diagnosis that is doubtful or unclear is checked with original hospital records. Therefore, diagnostic specificity is high (25). For spina bifida the sensitivity is estimated to be $80-90 \%$ (26).

Prenatally diagnosed malformations leading to elective abortions could not be included in the study. Theoretically this exclusion may have introduced some selection bias. However, it should be stressed that the majority of Swedish women get at least one ultrasound screening during pregnancy free of charge. As any possible effect of prenatal screening may be largest among the older mothers and in more recent periods, we stratified our analyses according to age and calendar year. No differences in the odds ratios were found between mothers above 27 years of age and those 27 years of age or younger. The differences between the women who gave birth before and after 1985 were also negligible.

Because the neural tube is closed in the fourth week of pregnancy, occupational exposure in the first month of pregnancy is of interest. However, information is recorded in the Medical Birth Register at weeks $10-12$ of pregnancy, and census information is collected at fiveyear intervals and linked with births in the following year. Therefore, occupation may have been misclassified if the recorded occupation was not the same as the occupation in the relevant period (27). As women usually do not stop working until the end of their pregnancy, we did not expect this type of misclassification to be large. Oc- cupations could be derived from the census in one-third of all cases and referents. Census information is usually not collected during pregnancy at all; however, because it is more complete and precise, census data were preferred to the Medical Birth Register. According to Ericson et al $(28,29)$, the accuracy of census information varied between $88 \%$ and $98 \%$. The fact that the information was collected before birth or even before pregnancy has the advantage that information on cases and referents with respect to exposures is comparable, and information bias is not likely.

A disadvantage of using routinely collected data is that the coding of occupations has received little attention when compared with specifically designed casereferent studies using questionnaires or interviews. In addition, a limitation of this study is that most of the other risk factors of interest, such as a family history of neural tube defects, consanguinity, dietary factors, vitamin use, and the use of anti-epileptic agents or ovulation stimulating agents, could not be taken into consideration in the analyses since information on these variables was not available in the Medical Birth Register or census. As a result, the odds ratios may be biased towards or away from the null value. A higher rate of consanguinity might theoretically be expected in rural populations, and such a difference might partly explain the increased odds ratio found for agriculture. However, this was not the case in our Dutch study on spina bifida and parental occupation (19), and so is therefore not expected in Sweden either. Adjustment for socioeconomic status and geographic area did not change the results. In The Netherlands, the only confounder was a family history of neural tube defects.

As information on paternal occupations was only available from census data in 1985, a small number of 81 case fathers and 162 reference fathers was included in the analyses. Therefore, the confidence intervals were wide and the point estimates for the paternal occupations have to be interpreted very carefully.

In the literature, some evidence is found for an association between spina bifida and maternal agricultural occupations. Although the risk observed in our study was only slightly increased, it agrees with the results reported in the literature. In a previous study in Sweden, Ericson et al (15) stated that no statistically significant association could be found between neural tube defects and any type of occupation, even though they did find an odds ratio of 7.1 for mothers in agricultural occupations. The $95 \%$ confidence interval, which was not presented because of small numbers, ranged from 1.4 to 35.2 . It is worth noting, however, that approximately one-third of the cases in our study was probably also included in the study of Ericson et al (15). A small-scale study in Venezuela showed largely differing frequencies of agricultural occupations among 76 cases of neural tube defects 
and 76 referents: $8 \%$ compared with $0 \%$ among the mothers and $32 \%$ compared with $13 \%$ among the fathers (14). Moreover, a study in England on congenital malformations among offspring of agricultural workers showed that "gardeners and groundsmen" had increased ratios for spina bifida, anencephaly, and facial clefts, while "agricultural workers" had increased ratios for spina bifida and facial clefts (11). In a questionnairebased case-referent study that we recently performed in The Netherlands, an increased risk of 5.6 (95\% CI 1.8 17.8) was found for women in agricultural occupations as well (19).

A specific teratogenic agent that might be responsible for the increased risk found in our study and in the literature could not be identified in this register-based study. However, directions for further and more-detailed research into the association between spina bifida and maternal agricultural occupations can be inferred.

\section{Acknowledgments}

This study was carried out at the Department of Embryology (Tornblad Institute), University of Lund, Sweden, and was financially supported by the Prinses Beatrix Fonds and The Netherlands Organization for Scientific Research (NWO).

The authors are obliged to A Ericson and J Gunnarskog $(\dagger)$ from the National Board of Health and Social Welfare in Stockholm, Sweden, for the linkage of the data and to B Källén for his help with the statistical analyses and his critical comments on the manuscript.

\section{References}

1. Little J, Elwood JH. Socioeconomic status and occupation. In: Elwood JM, Little J, Elwood JH, editors. Epidemiology and control of neural tube defects. Oxford: Oxford University Press, 1992:456-520. Monographs in epidemiology and biostatistics, vol 20.

2. Brown NA. Are offspring at risk from their father's exposure to toxins? Nature $1985 ; 316: 110$.

3. Hales BF, Smith S, Robaire B. Cyclophosphamide in the seminal fluid of treated males: transmission to females by mating and effect on pregnancy outcome. Toxicol Appl Pharmacol 1986;84:423-30.

4. Colie CF. Male mediated teratogenesis. Reprod Toxicol 1993;7:3-9.

5. Hemminki K, Mutanen P, Luoma K, Saloniemi I. Congenital malformations by the parental occupation in Finland. Int Arch Occup Environ Health 1980;46:93-8.

6. Hemminki K, Mutanen P, Saloniemi I, Luoma K. Congenital malformations and maternal occupation in Finland: multivariate analysis. J Epidemiol Community Health 1981;35:5-10.

7. Sikorski R, Juszkiewicz T, Paszkowski T, Sprengier-Juszkiewicz $\mathrm{T}$. Women in dental surgeries: reproductive hazards in occupational exposure to metallic mercury. Int Arch Occup
Environ Health 1987;59:551-7.

8. Matte TD, Mulinare J, Erickson JD. Case-control study of congenital defects and parental employment in health care. Am J Ind Med 1993;24:11-23.

9. Holmberg PC, Nurminen M. Congenital defects of the central nervous system and occupational factors during pregnancy: a case-referent study. Am J Ind Med 1980;1:167-76.

10. Olsen J. Risk of exposure to teratogens amongst laboratory staff and painters. Dan Med Bull 1983;30:24_8.

11. Balarajan R, McDowall M. Congenital malformations and agricultural workers [letter]. Lancet 1983;1:1112-3.

12. McDonald AD, McDonald JC, Armstrong B, Cherry NM, Nolin AD, Robert D. Fathers' occupation and pregnancy outcome. Br J Ind Med 1989;46:329 - 33.

13. Sever LE, Gilbert ES, Hessol NA, McIntyre JM. A casecontrol study of congenital malformations and occupational exposure to low-level ionizing radiation. Am J Epidemiol 1988;127:226-42.

14. Hammond FG, Canache MF. Some epidemiological aspects of neural tube defects in Barquisimeto, Venezuela [abstract]. Am J Hum Genet 1991:49 suppl: 470.

15. Ericson A, Källén B, Löfk vist $E$. Environmental factors in the etiology of neural tube defects: a negative study. Environ Res 1988:45:38-47.

16. Fedrick J. Anencephalus in the Oxford record linkage study area. Dev Med Child Neurol 1976;18:643-56.

17. Olshan AF, Teschke K, Baird PA. Paternal occupation and anomalies in offspring. Am J Ind Med 1991;20:447_ 75.

18. Brender CJ, Suarez L. Paternal occupation and anencephaly. Am J Epidemiol 1990;131:517-21

19. Blatter BM, Roeleveld N, Zielhuis GA, Mullaart RA, Gabreëls FJM. Spina bifida and parental occupation. Epidemiology 1996;7:188-93.

20. Blatter BM, Roeleveld N, Zielhuis GA, Gabreëls FJM, Verbeek ALM. Maternal occupational exposure during pregnancy and the risk of spina bifida. Occup Environ Med 1996; 53:80-6.

21. Nurminen T, Rantala K, Kurppa K, Holmberg PC. Agricultural work during pregnancy and selected structural malformations in Finland. Epidemiology 1995:6:23 - 30.

22. Källén B, Winberg J. Swedish register of congenital malformations: experience with continuous registration during two years with special reference to multiple malformations. Pediatrics 1968;41:765.

23. World Health Organization (WHO). International classification of diseases, ninth revision. Geneva, Switzerland: WHO, 1977.

24. Rothman KJ. Modern epidemiology. Boston (MA): Little, Brown and Company, 1986;237-83.

25. Ericson A, Källén B, Winberg J. Surveillance of malformations a birth: a comparison of two record systems run in parallel. Int J Epidemiol 1977;6:335-41.

26. Källén B, Löfkvist E. Time trends of spina bifida in Sweden 1947-81. J Epidemiol Community Health 1984;38:103-7.

27. Shaw GM, Gold EB. Methodological considerations in the study of parental occupational exposures and congenital malformations in offspring. Scand $\mathrm{J}$ Work Environ Health 1988:14:344 55 .

28. Ericson A, Eriksson $M$, Källén $B$, Westerholm $P$, Zetterström $R$. Delivery outcome of women working in laboratories during pregnancy. Arch Environ Health 1984;39:5-10.

29. Ericson A, Källén B. An epidemiological study of work with video screens and pregnancy outcome, II: a case-control study. Am J Ind Med 1986;9:459— 75.

Received for publication: 21 December 1995 